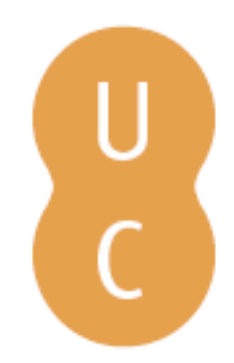

\title{
pompalina
}

\section{A face oculta da lua: reflexões sobre as relações entre o formal e o informal}

Autor(es): Ruivo, Fernando

Publicado por: Imprensa da Universidade de Coimbra

URL

persistente: $\quad$ URI:http://hdl.handle.net/10316.2/31321

DOI: $\quad$ DOI:http://dx.doi.org/10.14195/978-989-26-0222-6_4

Accessed : $\quad$ 26-Apr-2023 15:26:47

A navegação consulta e descarregamento dos títulos inseridos nas Bibliotecas Digitais UC Digitalis, UC Pombalina e UC Impactum, pressupõem a aceitação plena e sem reservas dos Termos e Condições de Uso destas Bibliotecas Digitais, disponíveis em https://digitalis.uc.pt/pt-pt/termos.

Conforme exposto nos referidos Termos e Condições de Uso, o descarregamento de títulos de acesso restrito requer uma licença válida de autorização devendo o utilizador aceder ao(s) documento(s) a partir de um endereço de IP da instituição detentora da supramencionada licença.

Ao utilizador é apenas permitido o descarregamento para uso pessoal, pelo que o emprego do(s) título(s) descarregado(s) para outro fim, designadamente comercial, carece de autorização do respetivo autor ou editor da obra.

Na medida em que todas as obras da UC Digitalis se encontram protegidas pelo Código do Direito de Autor e Direitos Conexos e demais legislação aplicável, toda a cópia, parcial ou total, deste documento, nos casos em que é legalmente admitida, deverá conter ou fazer-se acompanhar por este aviso. 
Sílvia Portugal

Paulo Henrique Martins

Organização

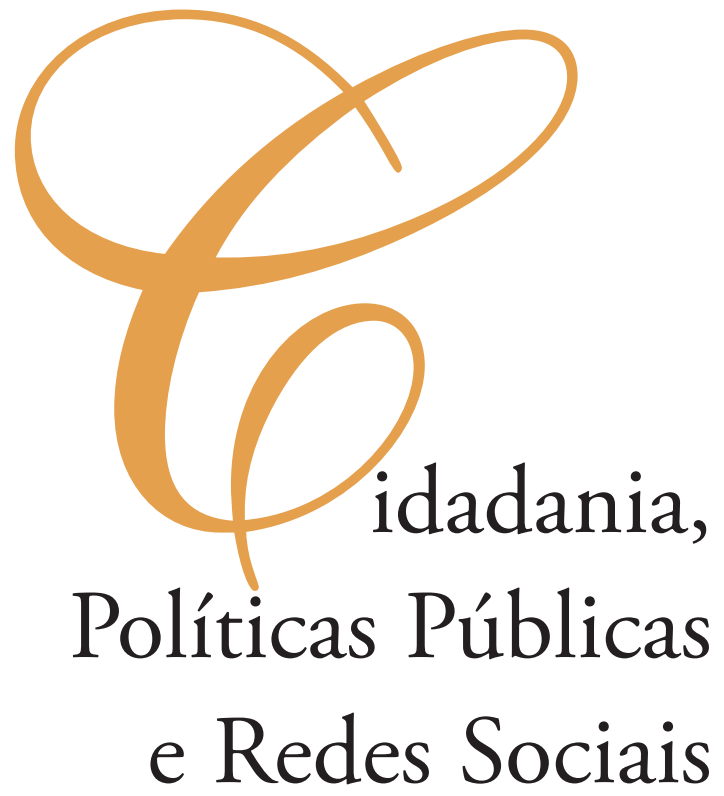


Fernando Ruivo

\section{A Face Oculta da Lua: \\ REFLEXófes SOBRE AS RELAÇÓES ENTRE O FORMAL E O INFORMAL}

O mundo formal e oficial, as suas regras e os seus jogos discursivos, bem como aquilo que se convencionou designar como a "esfera autêntica" e politicamente séria das políticas públicas ${ }^{1}$ escondeu durante muito tempo um outro segundo mundo, um mundo composto de muitas subtilezas e nuances, um mundo, por assim dizer, de enorme complexidade. A formalidade apresentava-se, deste modo, sob vestes categóricas, absolutas e normativas, procurando atribuir-se a exclusividade das regras do jogo no que dizia respeito aos variados patamares e produtos das formas de regulaçáo da vida social.

Estávamos, no entanto, perante como que uma "fachada", e o formal, essa ponta visível do iceberg, para utilizar a bem sucedida expressão de Berger e Luckman (1985), tendia, assim, a atrair a generalidade dos olhares e a concentrar as atençôes, por essa via se ocultando um outro mundo, a verdadeira base material submersa (e portanto náo imediatamente perceptível) de sustentação desse iceberg, aquilo que poderia conduzir à compreensão mais completa, intensa e idónea da complexidade dos fenómenos que se pretendem analisar.

A este segundo mundo, um mundo portanto tendencial e intencionalmente ignorado, nunca foi tradicionalmente atribuída grande importância pelo segmento "nobre" da vida social, o qual o encarava como um elemento altamente secundário (como que um fait divers), como algo portador de um estatuto de irracionalidade e cuja intromissão no curso dos acontecimentos (bem como na sua explicação) devia, na medida do possível ser, enquanto factor eminentemente subjectivo, acautelada ${ }^{2}$. Por analogia, era como que a face oculta da lua, aquela face que, apesar de sabermos existir, parece tornar-se, à primeira vista, impraticável e, até, manifestamente inútil procurar escrutinar...

${ }^{1}$ Esta "autenticidade" postulava simplesmente que bastava definir hierárquica e centralmente essas mesmas políticas para que elas fossem racional, capilar, automática e homogeneamente implementadas por um aparelho cego e obediente de funcionários administrativos, totalmente instrumentais em relação ao interesse definido pelo Estado, bem como à sua esfera pública, separados das esferas privadas e imunes a quaisquer outras formas de influência. Tudo isto mergulha, evidentemente, nos velhos mitos administrativos construídos no final do século XIX, em consonância com a construção histórica da noção do então Estado de Direito. Os percursos do final do século XX demonstraram, para o bem ou para o mal, que a realidade se apresenta de forma bem diferente. A propósito destes percursos, teóricos e históricos, cf. a contribuição de um administrativista excepcionalmente bem atento, Timsit (1986: 169 ss.).

2 O que reflectia o predomínio e o monopólio do registo e da narrativa objectivista sobre o conjunto da vida social. 
Este segundo mundo a que nos referimos tem vindo a ser denominado como o mundo do informal ${ }^{3}$. E a marginalizaçáo deste mundo informal por parte do senso comum em geral (e do político, em particular do politicamente correcto) veio a ser seguida pela esmagadora maioria, salvo honrosas excepçóes (as quais procuravam acentuar a possibilidade de diversas e diferentes racionalidades em presença ${ }^{4}$ ), das preocupaçóes clássicas (muito especialmente, em termos políticos), redutoras e igualmente "nobres" das Ciências Sociais em geral. Até um determinado momento do século passado, deste modo, o informal tendia, pois, a ser predominantemente silenciado e considerado como pouco importante ou náo estruturante para todo o processo de construção social da realidade, bem como para todos os outros múltiplos sub-processos que vão compondo essa mesma construção 5 .

Olhando para trás, no entanto, podemos constatar que alguns marcos importantes contribuíram para progressivamente irem desconstruindo este mesmo modelo ou configuração, para alterar a incidência do olhar e da narrativa e, por essa via, contribuir para afirmar a importância do universo da informalidade, bem como dos efeitos não esperados que com ela podem ser carreados. Este facto em muito veio enriquecer a consistência e a produtividade das análises posteriormente advindas. Entre esses muitos marcos, salientemos e relembremos apenas três, os quais se revestiram de grande importância para a referida alteração do olhar e, consequentemente, da narração ${ }^{6}$.

1. Em finais da década de quarenta do século passado, Philip Selznick (1949) publicava uma obra de referência para o universo anglo-saxónico. Intitulava-se "TVA and Grass Roots" e nela o autor discorria sobre o trabalho da denominada Tenessee Valley Authority nos Estados Unidos em torno da regulação do leito do rio Mississipi e da implementação de projectos integrados de desenvolvimento sócio-económico envolvendo as populaçôes dessa

${ }^{3}$ É extremamente sintomática a definição que o Dicionário Houaiss da Língua Portuguesa, um dicionário considerado de referência obrigatória (2003: 2094) nos dá deste termo: o "que náo aparece ou se recusa a aparecer sob uma forma definida". O problema, quanto a nós, é que o informal, como tentaremos demonstrar, aparece sempre e, bem pelo contrário, nunca se recusando a aparecer. Aquela definição constituirá assim uma manifestaçáo do ponto de vista oficial. Afinal, o informal predomina, em coexistência com o formal, embora sob formas não previstas, reconhecidas e pré-definidas. De registar igualmente, o que parece altamente significativo em matéria linguística (e tudo aquilo que ela revela sobre as representaçôes sociais que nela se inscrevem), que a palavra náo consta de outros dicionários (de uso mais corrente?) consultados, tendo a sua definiçáo, neles ausente, de ser elaborada em contraposição ao termo formal (esse sim sempre presente, com remissōes para o contexto da cerimónia e do ritual). A linguagem, como se percebe, pode conter também outros patamares de linguagens, estes de silêncios e ausências, os quais necessitam, igualmente de ser socialmente lidos e compreendido.

${ }^{4}$ A propósito deste tema e do fim do mito da racionalidade, única e central, do contexto Weberiano, cf., entre outros, Crozier (1971: 218 ss.), Timsit (1986: 190 ss.) e Ruivo (2000a e b).

5 Santos (1988), a propósito da regulaçấo da vida social, revê os três modelos dessa regulaçáo (os pilares da hierarquia, do mercado e da comunidade), criticando a visão exclusivista de qualquer um deles e propondo formas complexas de articulação entre eles. Relativamente a este tema, pela nossa parte (Ruivo, 2000a: 41 ss.), avançou-se com a noção de um outro pilar de regulação, o pilar reticular, constituído por redes sociais e componentes de densidade fortemente informal.

${ }^{6}$ Esta alteração do olhar é simultaneamente acompanhada por uma transição paradigmática narrativa de igual relevo: a transição da análise top-down das políticas públicas para o seu enfoque bottom-up. Sobre o assunto, cf. Ruivo (2002). 
área daquele Estado ${ }^{7}$. A partir da análise que então efectuou sobre o processo em curso, algumas das conclusôes que vem a apresentar acabam por assumir um carácter verdadeiramente demolidor para aquilo que se encontrava então ainda solidamente estabelecido: a execução hierárquica, obediente, uniforme e homogénea das políticas públicas em todos os territórios a que se destinavam. Contrariando esta postura, Selznick deduz do seu trabalho de campo que face ao modelo formal de política inicialmente proposto, a conjugaçáo localizada e informal de técnicos, políticos estaduais e locais, de elites territoriais, de grupos de pressão e burocratas, entre outros actores do naipe envolvido na execução in loco, viria a conduzir a que a política primeiramente pensada em termos formais viesse a obter vários e muito diferentes tipos de concretizaçôes e registos territoriais ${ }^{8}$.

2. Bem mais tarde, já na década de setenta, agora do lado francês, Pierre Grémion publica o seu "Le Pouvoir Périphérique: bureaucrates et notables dans le système politique français” (1976). Nesta obra aborda também a execução das políticas públicas, concluindo similarmente e de forma igualmente demolidora, ora para o espaço europeu, que aquilo que central e inicialmente tinha sido magicado e desenhado enquanto política pública só parcial ou de forma localmente adaptada se viria a concretizar'. Este facto decorria, segundo Grémion, do jogo que se operava entre funcionários territoriais e redes notabiliares territoriais no seio daquilo que ele designava como o "sistema político-administrativo local" 10 . Ora, este jogo de ping-pong, se assim o podemos designar, um jogo desenvolvido numa atmosfera altamente informal, alterava e alterava definitivamente, na sua opinião, todo o enquadramento jurídico-formal pensado para regular a realidade do sistema político local e a própria concretização local das políticas ${ }^{11}$.

3. E, um pouco mais tarde ainda, em 1980, novamente do lado anglo-saxónico, Peter Hall publica um título que ele próprio, na apresentação, considera parecer sensacionalista

7 O modelo TVA foi posteriormente, nos anos oitenta, exportado para o exterior dos EUA no quadro da cooperação para a modernização e o desenvolvimento. Em Portugal a colaboração concretizou-se, por exemplo, no projecto Merec-Regiāo Centro, envolvendo algumas Câmaras Municipais e a entáo Comissão de Coordenação da Região Centro.

8 Era, para a altura, uma novidade e uma heresia, enunciada à revelia do que se pensava na Europa de então. E que apontava já para algo que seria mais tarde afirmado noutro local, a propósito do contexto português: "a política desdobrar-se-á numa multiplicidade de tipos de execução de medidas políticas e de formas de acçáo política que ora assumirão aqui determinado cariz, ora ali tomarão outro figurino. Qual ou quais as variáveis que influenciam esta situação? Entre outras, a variável do 'aqui' e do 'ali', a variável dos diferentes locais, dos seus agentes e das suas especificidades” (Ruivo, 2000a: 15). A este propósito, $c f$. ainda, para o caso das políticas sociais (Ruivo, 2000b).

9 A esta conclusão não terá sido alheio o contacto do autor com a produção norte-americana durante uma estadia em Harvard no início da década de setenta (1971). Bem como, evidentemente, a sua participação no Centro de Sociologia das Organizaçóes francês e o impulso e direcção deste trabalho (que retoma parcialmente a tese "Pouvoir local, Pouvoir central: essai sur la fin de l'administration républicaine", apresentada na Universidade René Descartes) por parte de Michel Crozier.

10 Definido como um "poder local que se encontra no ponto de intersecção do aparelho burocrático do Estado com as instâncias de representaçóes locais" (1976: 150). "Este sistema (...) permitiria romper com 'um esquema central/vertical de interpretação do comportamento das pessoas nas estruturas administrativas' e estabelecer, na sua vez, um outro, que designa como periférico/horizontal, manifesto numa 'rede de interacçóes' entre actores" (Ruivo, 2000a: 56).

11 Passados alguns anos, Corcuff e Lafaye (1989) reafirmavam a continuada actualidade deste trabalho de Grémion. 
mas, simultaneamente constituir, na sua opinião, uma "descrição razoavelmente exacta" do que então se passava (1980: 1). A obra intitulava-se significativamente "Great Planning Disasters" e discorria sobre a incerteza, os desastres negativos ${ }^{12}$, os desastres positivos ${ }^{13} \mathrm{e}$, essencialmente, sobre aquilo que o autor designa como a "patologia dos processos de planeamento”. Isto é, a forma como as decisôes são tomadas e, depois, ou abandonadas ou continuadas face ao volume das críticas e pressóes por parte das diferentes entidades de algum modo envolvidas (1980: 3) $)^{14}$. A comunidade ou comunidades, a burocracia, os políticos de variados quadrantes, segmentos da sociedade civil, bem como a concertaçáo de todos estes actores para além do quadro formal constituem aqui o objecto da análise. O processo de implosão de tudo aquilo que dominantemente se pensava está, assim, em plena marcha e em processo de consolidação, como se pode bem entender ${ }^{15}$.

Ora, o que se passou neste processo de implosão teórica foi o assumir da coexistência de um modelo hierárquico-formal com um outro de cariz mais horizontal-informal. Um processo que é despoletado num determinado território, um território que ostenta características e especifidades que se apresentam como marcantes e onde pontuam diferentes actores. Este traço, possibilitado pelo regresso dos actores ao âmago da cena, do jogo dos actores numa margem ou zona de incerteza ${ }^{16}$, para utilizar as palavras de Bernoux (1985: 138), é, pois e deste modo, determinante para a configuração do produto final de cada política pública localizada ${ }^{17}$.

Procurar visualizar, portanto, os laços e interacçóes existentes entre as práticas informais, bem como entre estas e o próprio sistema formal revela-se, na actualidade, como uma tarefa de extrema importância para as Ciências Sociais em geral, e isto, tanto em termos teóricos como em termos empíricos ${ }^{18}$. Bem como, visibilizar tais laços, com uma especial incidência na articulação entre redes e políticas públicas. É que todas as operações de engenharia, as quais constituem a concepção da armação ou travejamento de uma política

12 Ou abandono de projectos planeados. Por exemplo, o terceiro aeroporto de Londres (começado a ser pensado em 1967, Stansted, e ainda não construído no ano de 1979), bem como as trezentas e cinquenta milhas de auto-estradas conducentes a Londres (pensadas no final da II Grande Guerra e abandonadas, com quarenta milhas executadas, em 1973) ou o túnel do Canal (Hall, 1980: 2). Repare-se que se trata de abandonos, entre outros, pensados como tal nesse período, tendo o futuro ditado outro curso aos acontecimentos...

13 "Decisóes com resultados físicos que foram implementadas apesar de muito criticismo e, até, oposição, tendo sido mais tarde considerados como um erro por muitos detentores de informação" (Hall, 1980: 2). Entre outros, o Concorde e a Ópera de Sydney.

${ }^{14}$ Estas hipóteses de trabalho são extremamente interessantes se quisermos elaborar uma analogia com o caso português da última década no que diz respeito à localização do novo aeroporto (Ota? Alcochete? Poceirão? Rio Frio?) e ao próprio traçado da rede de alta velocidade, o TGV.

15 Por esta via se desocultando um pouco, dado o papel crescente da comunicação social, a mencionada face oculta da lua.

${ }^{16}$ Esta zona de incerteza ou, se quisermos, margem de manobra, produzida pelos contingências do ambiente em que os actores se movem constitui, como se entende, uma fonte de poder, residindo esta fonte na possibilidade de instaurar processos amplos de negociação (Bernoux, 1985: 138).

${ }^{17}$ Face às concepçóes até entâo dominantes, pode fazer-se uma analogia, salvo as devidas distâncias, com o discurso de Charles Fourier no decurso do século XVIII: "c'est un monde à rebours", isto é, trata-se, visto desta forma, de um "mundo de pés para o ar" relativamente ao mundo das anteriores formas de pensar.

${ }^{18}$ Como podemos desde já antecipar, os universos correspondentes ao formal e ao informal não se encontram, de modo algum, separados, não possuem características totalmente antitéticas, nem se encontram, à partida, animados de lógicas absolutamente contrárias. Uma ilustração desta afirmação pode ser encontrada em Ruivo (2000a). 
pública por parte dos altos decisores hierárquicos, são depois necessária e posteriormente submetidas, frise-se, a uma outra generalidade de operaçôes. Podemos designar estas manobras como intervenções de reengenharia. Trata-se de operaçóes informais desenvolvidas a outra escala, muitas vezes de incidência apenas local ${ }^{19} \mathrm{e}$, claro está, altamente dependentes das características dos variados actores que as adaptam, modificam ou, até, eventualmente, curto-circuitam, a fim de as poder ou não executar...

Podíamos citar Gabriel Garcia Marquez (2002: 125) a este propósito, quando ele afirma a determinado momento que "os romances não começam como queremos mas como eles querem”20. Passe a heresia, tão só aparente, também as políticas públicas assim se comportam. Elas, as políticas, não começam material e exactamente como foram delineadas ao centro. Desenvolvem-se em contextos que não foram os inicialmente previstos, já que os diferentes territórios de execução não possuem, obviamente, carácter homogéneo. Sofrem o manuseamento e adaptaçóes de actores colocados em diferentes patamares e lógicas, desdobrando-se, muito especialmente, tal como os romances, em ritmos muito alheios aos seus remotos autores, tanto a romancistas como a planeadores ${ }^{21}$. Trata-se do jogo das personagens e dos actores mais directamente ligados ao terreno (à história que se pretende contar ou materialmente edificar) e que aí se encontram colocados.

Tudo o que atrás foi exposto aponta, portanto, para o facto de as actividades formais possuírem aspectos informais ${ }^{22}$. Ora, estes últimos, os informais, o "manobrar por detrás da cena”, necessitam de ser descodificados, desconstruídos e analisados na sua relação com o formal, a fim de que se possam cabalmente compreender a complexidade de determinados processos e produtos sociais. É que este "manobrar" constitui um ethos de informalidade em que qualquer um de nós parece participar, apesar de tal situação não ser explicitamente reportada ${ }^{23}$. Trata-se da questão da "área cinzenta" da vida social em que toda esta actividade ostenta uma densidade que pode surpreender qualquer observador mais atento. Acresce que essa mesma actividade não se apresenta como algo de meramente pontual ou ocasional, encerrando em si uma grande consistência.

A este propósito, deve, no entanto e desde logo, entender-se, como atrás foi esboçado, que o sistema informal não é uma entidade distinta e totalmente separada do sistema formal. O sistema informal deve ser visto, para utilizar a formulação de Peter Fitzpatrick

19 Embora possam contar, por razóes funcionais, com o beneplácito ou anuência oficiosa de outras escalas e patamares do sistema sócio político.

${ }^{20}$ O imponderável e complexo processo histórico de transformação de necessidades sociais, submetidas a lutas e a diferentes mecanismos antagónicos de censura, filtragem ou afirmação, em políticas públicas (ou seus correspondentes retrocessos) ilustra bem esta afirmação.

${ }^{21}$ Poderíamos aqui acrescentar, por analogia, uma continuação do raciocínio de Garcia Marquez: (os romances), as políticas públicas e as "histórias de vida" dos actores nelas envolvidos desenvolvem-se como podem. Daí que devam ser analisadas "não tanto pelos seus nomes como pelas suas vidas secretas" (Marquez, 2002: 186).

22 E vice versa, ou seja, o facto de as actividades ou produtos informais pressuporem aspectos ou contextos de formalidade. Podemos, deste modo, a este propósito, formular o seguinte enunciado: toda a formalidade comporta informalidade, bem como toda a informalidade alberga formalidade.

${ }^{23}$ E não explicitada devido à natureza altamente sensível em termos sociais (de ordem pessoal, possivelmente menos ética ou, até, de natureza alegal) das actividades que informalmente se desenvolvem para formatar o produto formal. 
(1988), não apenas como um sistema instrumental relativamente a um poder ou manifestação formal, mas como algo constituído por esse próprio poder formal no seu interior ${ }^{24}$.

Deve entender-se, deste modo, que o formal não existe, portanto, sem o informal. E compreender-se, para além do mais, que formal e informal são duas facetas complementares (mesmo que opostas ou adaptadoras) da mesma realidade, as quais contribuem de diferentes e muitas diversas maneiras para os, igualmente, muito variados produtos sociais finais.

Formalidade e informalidade serão, assim, duas faces de um mesmo processo, reflectindo a realidade sociológica do carácter multifacetado da vida social e quotidiana. Nessa medida, os processos de políticas locais formais não poderão ser inteiramente compreendidos sem se prestar a devida atenção à informalidade que eles próprios contêm e veiculam, desse modo contribuindo para modelar os seus conteúdos.

\section{Passemos então a sintetizar, em termos de conclusão.}

As políticas da informalidade podem caracterizar-se como um instrumento que providencia ao sistema formal todo um leque de actividades de que este necessita, as quais este último processa e às quais é forçado a reagir. Poderemos, assim, encontrar uma ou várias das seguintes situaçôes ${ }^{25}$ :

a) $\mathrm{O}$ informal como coadjuvante de resolução de problemas: o informal pode constituir-se como um espaço onde determinados problemas, constrangimentos e emperramentos de ordem variada, iniciados no domínio formal e oficial, podem vir a encontrar resolução. E, na realidade, o informal encontra-se apto para lidar eficientemente com este tipo de situaçôes, já que ao seu nível se podem concretizar oficiosa e sigilosamente negociaçôes e acordos de carácter menos "racional" 26 ou alegal ${ }^{27}$ que propiciem o desbloqueamento de circunstâncias de carácter mais melindroso;

b) Neste sentido, o informal pode vir a consubstancia-se como uma espécie de "ensaio por detrás do palco" (back stage) onde decorre o processo oficial: assim, ao perspectivar compromissos e estratégias adaptativas de actuação entre actores, o informal pode auxiliar o sucesso no palco (front stage) por parte do formal;

c) O informal como compromisso de válvula de segurança: ao possibilitar novas e últimas tentativas de negociaçáo, o informal constitui-se, deste modo, como o mecanismo que pode impedir uma completa e total falta de controlo das operaçóes por parte do sistema formal e oficial;

d) O informal como alimentador de eficácia no sistema de comunicação: os agentes organizacionais necessitam de informaçóes sobre o meio ambiente que procuram operacio-

\footnotetext{
${ }^{24}$ A diferença que decorre desta formulação reside no facto de, a partir daqui, podermos passar a olhar o sistema no seu todo como uma entidade que inclui uma ampla diversidade de espaços, os quais operam simultaneamente em diferentes escalas e registos, bem como integrando diferentes posiçóes interpretativas.

${ }^{25}$ Cf. a este propósito, Laguerre (1994).

${ }^{26}$ Ou impregnados de outras racionalidades existentes em campo, bem como produtos derivados de outras lógicas.

27 Nem legais, nem ilegais. Isto é, posicionados na vasta escala de cores intermédias situadas entre os extremos (o preto e o branco) que compóem toda a paleta das cores de que afinal se encontra composta a vida social.
} 
nalizar a seu favor. A comunicação carreada a partir do informal para o interior do formal, através da relaçấo com mediadores, tradutores e interlocutores privilegiados posicionados no seu exterior, permite o acesso a informação de grande utilidade, imprescindível para uma operacionalização adaptativa (devido à tradução efectuada), a qual será muito difícil de obter de outro modo;

e) A informalidade como possível patamar de resistência: apesar de, em boa parte dos casos, a informalidade aparecer com funçóes positivas e equilibrantes de coadjuvaçáo adaptadora do sistema formal, ela poderá constituir simultaneamente uma poderosa e eficaz plataforma estratégica de construção de oposição transformadora. Oposição a agentes ou líderes do sistema formal, bem como alteração de intervençôes desencadeadas por sua iniciativa.

Poderemos, pois, concluir que muito se pode compreender a partir de uma concepçáo que abarque uma cooperaçáo adaptativa entre os dois componentes do sistema, o formal e o informal. É que o sistema formal constitui um espaço que compreende muitos outros espaços onde, quer simultaneamente, quer sucessivamente, ocorrem actividades formais e informais. Estando o sistema informal incluído no espaço formal mais vasto, a informalidade encontra-se definitivamente relacionada com a topografia do sistema social formal, constituindo, pois, como que uma província desse mesmo sistema.

\section{Referências bibliográficas}

BERGER, Peter e LUCKMAN, Thomas - A Construção Social da Realidade. Petrópolis: Editora Vozes, 1985. BERNOUX, Philippe - La Sociologie des Organisations. Paris: Seuil, 1985.

CORCUFF, Philippe e LAFAYE, Claudette - "Une relecture critique du Pouvoir périphérique". Politix. 7/8, 1989. CROZIER, Michel - Le Phénomène Bureaucratique. Paris: Éditions du Seuil, 1971.

FITZPATRICK, Peter - “The Rise and Rise of Informalism”. In Matthews, Roger, Informal Justice. London: Sage, 1988.

GRÉMION, Pierre - Le Pouvoir Périphérique: bureaucrates et notables dans le système politique français. Paris: Seuil, 1976.

HALL, Peter - Great Planning Disasters. London: Weidenfeld and Nicholson, 1980.

HOUAISS, Antônio - Dicionário Houaiss de Lingua Portuguesa, Tomo IV (FRE-MER). Lisboa: Círculo de Leitores, 2003.

LAGUERRE, Michel - The Informal City. London: MacMillan Press, 1994.

MARQUEZ, Gabriel García - Viver para contá-la. Lisboa: Dom Quixote, 2002.

RUIVO, Fernando - O Estado Labirintico: O Poder Relacional entre Poderes Central e Local em Portugal. Porto: Afrontamento, 2000a.

RUIVO, Fernando - Poder Local e Exclusão Social: Dois Estudos de Caso Sobre a Organização Local de Luta Contra a Pobreza. Coimbra: Quarteto, 2000b.

RUIVO, Fernando - "Localização de Políticas Públicas". Oficina do CES. n. o 178, 2002.

SANTOS, Boaventura de Sousa - "O social e o politico na transição pós-moderna”. Oficina do CES. nº1, 1988.

SELZNICK, Philip - TVA and Grass Roots. Berkeley: University of California Press, 1949.

TIMSIT, Gérard - Théorie de l'Administration. Paris: Economica, 1986. 